\title{
1980 NEST CENSUS OF SASKATCHEWAN'S PELICAN AND CORMORANT COLONIES
}

KEITH RONEY, Saskatchewan Museum of Natural History, Regina, Saskatchewan. S4P 3V7

A 1980 census of White Pelican and Double-crested Cormorant nests was conducted in Saskatchewan as part of a continuing program to monitor the nesting status of these species in the province. Twelve pelican and seventeen cormorant colonies were surveyed with a total of 15,427 and 7,410 nests counted respectively. This represents an increase in numbers of both pelican and cormorant nests since the 1978 survey.

\section{Methods}

The census was conducted from 30 May - 7 June at what should be the height of incubating activity. Survey time ranged from 0745 to 0915 (Central Standard Time). The Cypress Lake colony was surveyed from the ground and all incubating adults were counted to determine the number of active nests. All the other colonies were surveyed by means of aerial photographs taken from a plane window with a handheld Pentax KX camera and a $200 \mathrm{~mm}$ lens. Kodachrome 64 color slide film was used. All photos were taken from a minimum altitude of $230 \mathrm{~m}$ as close as possible to vertical. This height did not disturb the birds. The slides were examined under a binocular microscope to count incubating adults.

The Preston Lake colony was surveyed by the Canadian Wildlife Service in Saskatoon. A report of cormorants nesting at Reed Lake was received late in the summer and was checked 18 August.

\section{Results and Discussion}

Twelve active pelican colonies located on nine different waterbodies were surveyed in 1980. Quill, Suggi and Primrose Lakes each contained two nesting islands. The total was 15,427 nests (Table 1). This is an increase of 3,148 nests or $26 \%$ over the 12,279 nests recorded in 1978.' All colonies maintained or increased their numbers with the exception of the Kazan Lake colony which decreased from 952 nests to 768 nests.

The Old Wives Lake colony remained stable while Lavallée and Primrose Lake colonies showed moderate increases of 771 and 827 nests respectively and Redberry, Quill and Suggi Lakes experienced sharp increases in colony size of 96,423 , and 839 nests respectively. Even though the latter increases appear less dramatic than for the Lavallée and Primrose Lake colonies, the actual percentage and relative increase in the size of these colonies was greater. Lavellée Lake colony increased by $26 \%$ and Primrose Lake colony by $21 \%$ while Redberry Lake colony increased by $133 \%$, Quill Lake by $182 \%$, and Suggi Lake by $92 \%$. Kazan Lake colony decreased by $19 \%$.

The colonies at Preston and Lenore Lakes were first surveyed in 1980. Although only recently reported and checked, these colonies have been in existence for a number of years. In 1935, Mr. S. C. Ells, a geologist with the Geological Survey, studied and photographed a colony of about 150 adult 
Table 1. CENSUS OF PELICAN AND CORMORANT COLONIES IN SASKATCHEWAN, 1980

Location

Preston Lake ${ }^{\mathrm{a}}$

Old Wives Lake

Last Mountain Lake

Quill Lake

Cypress Lake ${ }^{b}$

Redberry Lake

Lenore Lake ${ }^{\mathrm{C}}$

Suggi Lake

Lavallée Lake

Doré Lake

Primrose Lake

Kazan Lake

Churchill Lake

Reed Lakec

\section{Date}

May 18

May 30

May 31

May 31

June 2

June 4

June 4

June 5

June 6

June 6

June 7

June 7

June 7

Aug. 18
Pelican Nests

Cormorant Nests

693

$789(2)^{\mathrm{d}}$

75 (2)

283

43

670

1,153 (2)

747

849 (2)

459 (2)

1,587

768

-

62

a - Surveyed by C.W.S.

b - Ground survey

c - First surveyed in 1980

$\mathrm{d}$ - Indicates number of nesting islands, if more than one

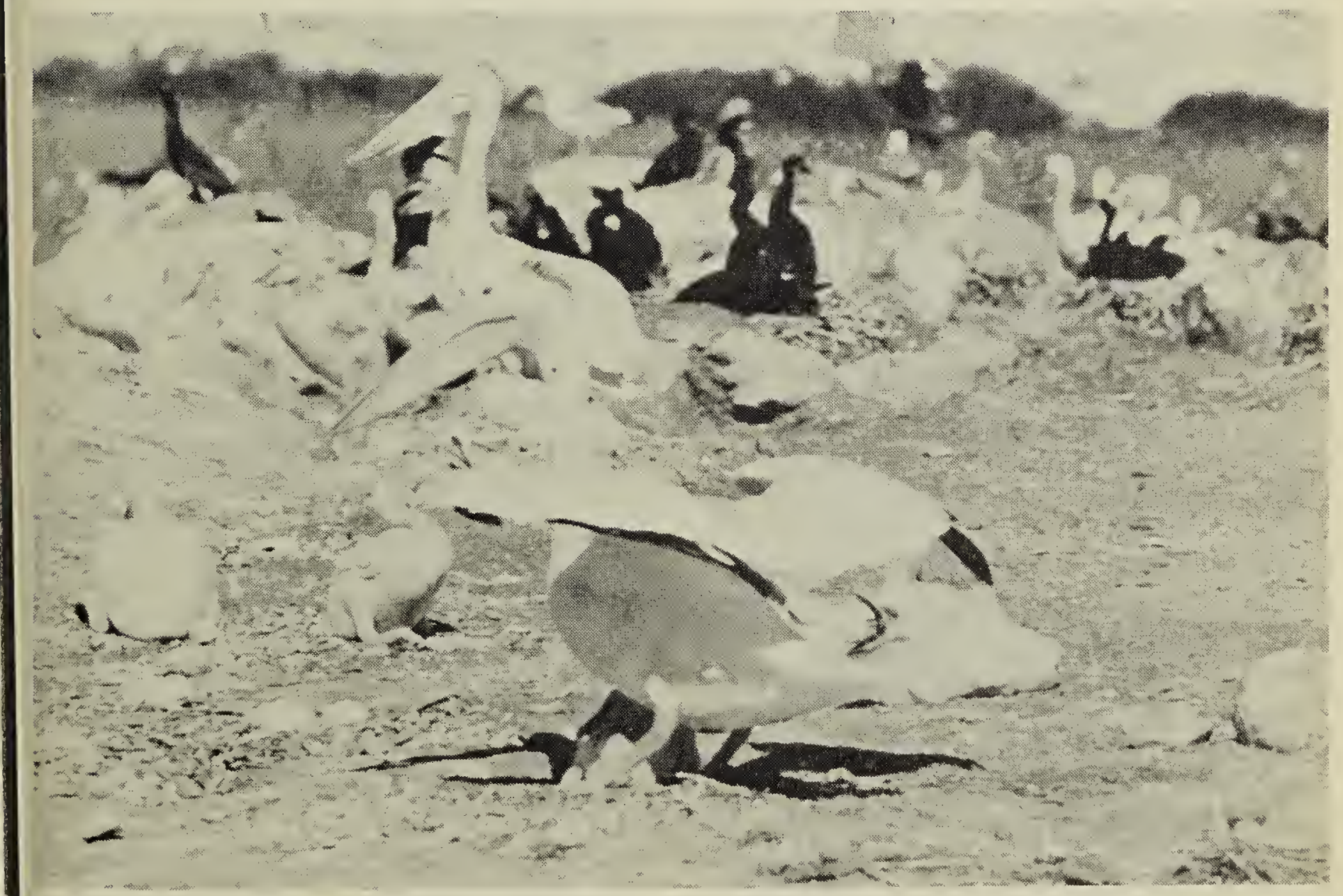

Pelican/cormorant colony, Quill Lakes.

Keith Roney 


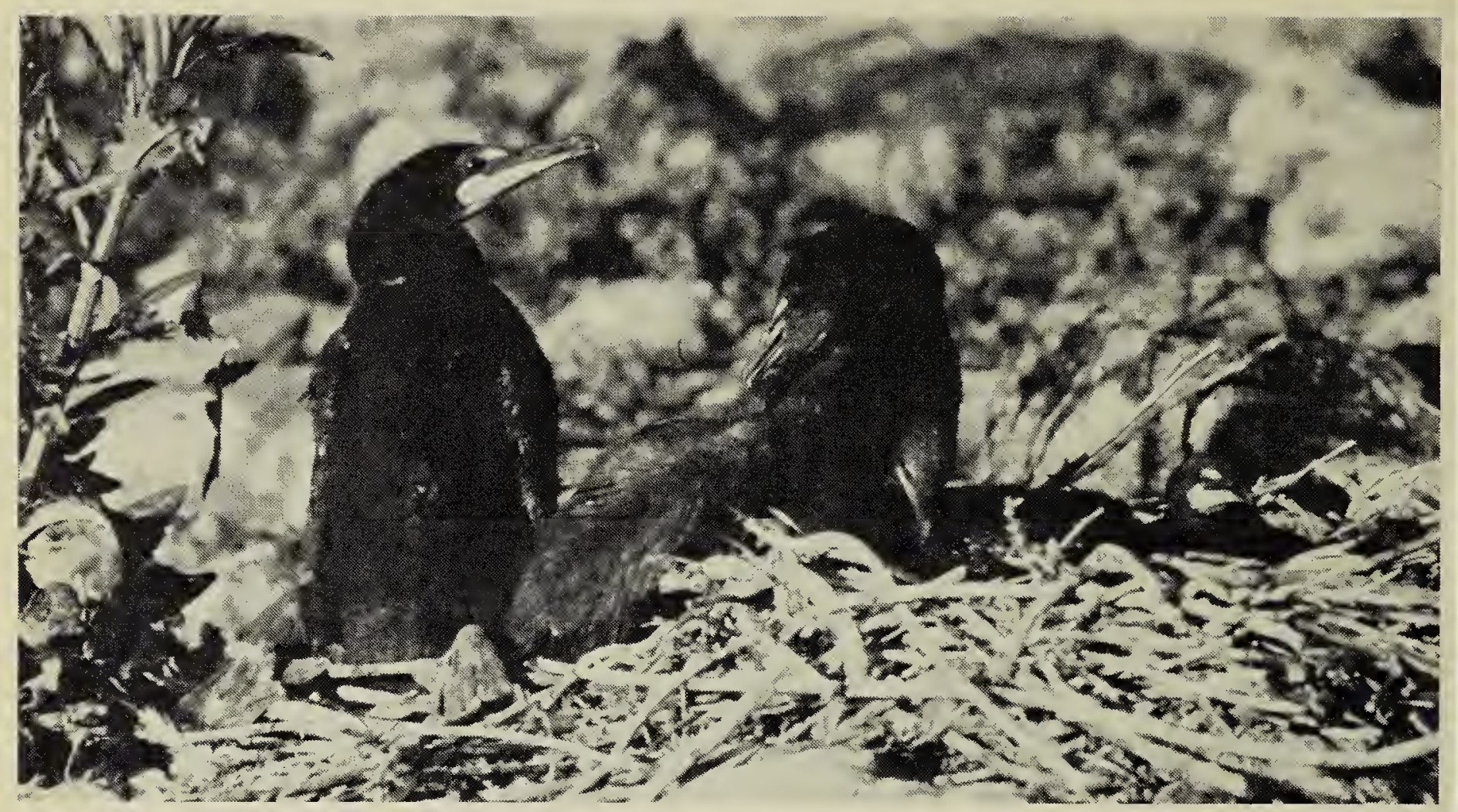

Double-crested Cormorants.

Juhachi Asai

pelicans on an island in Preston Lake (W. E. Godfrey, pers. comm.). Residents in the vicinity of Lenore Lake indicated that this colony had been active for many years (D. Mevel, pers. comm.).

Seventeen active cormorant colonies located on twelve different water-bodies were surveyed in 1980. Two nesting islands were located on each of Last Mountain, Quill, Suggi, Doré and Primrose Lakes. The count was 7,410 nests (Table 1). This is an increase of 3,443 nests or $87 \%$ over $1978 .{ }^{1}$ Old Wives and Quill Lake colonies remained stable while a moderate increase of $15 \%$ occurred on Lavallée Lake. Increases of $134 \%$ occurred in Last Mountain Lake, $79 \%$ in Redberry, $99 \%$ in Suggi, $214 \%$ in Doré, $270 \%$ in Primrose and $111 \%$ in Kazan Lake. The Cypress Lake colony declined by $28 \%$ and the Churchill Lake colony which contained 104 nests in 1978 was deserted in 1980.

Lenore Lake was first surveyed in 1980. A cormorant colony at Reed Lake was reported late in the summer (C. Harris, pers. comm.) and 62 nests were counted on 18 August.
The numbers of White Pelican and Double-crested Cormorant nests have been increasing since the monitoring program began in 1976. Local colony production and/or recruitment from other colonies have been sufficient to replace any losses. The total increase may be due to increased management and monitoring of these species. There is also increasing awareness of and concern for native wildlife by the general public.

\section{Acknowledgments}

I wish to thank Bill Russon for his assistance with the field census. I am grateful to Mr. Bruce Wilson, Superintendent, Prince Albert National Park, and the Department of National Defence, Medley, Alberta for granting permission to survey the Lavallée Lake and Primrose Lake colonies, respectively. Thanks are also extended to the many capable pilots involved in the aerial census.

'RONEY, K. 1979. Saskatchewan's Pelicans and Cormorants in 1978. Blue Jay $37(4): 216-218$. 